Journal of Systems Science and Information

Oct., 2015, Vol. 3, No. 5, pp. 451-462

DOI: 10.1515/JSSI-2015-0451

\title{
Research on the Evaluation of Enterprises' Green Growth Efficiency Based on DEMATEL-DEA
}

\author{
Xinghong CHEN \\ Faculty of Management and Economics, Dalian University of Technology, Dalian 116024, China \\ E-mail: chanchang@vip.sina.com \\ Chunyou WU \\ Faculty of Management and Economics, Dalian University of Technology, Dalian 116024, China \\ E-mail: wucy@dlut.edu.cn \\ Haibo KUANG \\ School of Transportation Management, Dalian Maritime University, Dalian 116026, China \\ E-mail: dlmukhb@189.cn
}

\begin{abstract}
With the transformation of economic growth modes, green growth is becoming the main source of global economic growth for the future. Enterprises are the main carriers of the economic growth in a country or a region, and enterprises' green growth efficiency determines the regional sustainable growth ability. On this basis, this paper investigates the problem of enterprises' green growth efficiency in China and identifies the input and output indexes of the green growth using the DEMATEL method. Then, through the super efficiency DEA model, this paper measures the enterprise green growth efficiency of 31 regions in China in the years 2003, 2007 and 2012. In accordance with the four parts, including the East, the Central, the West and the Northeast, this paper completes a spatial and temporal variation analysis. The results show that there is an obvious regional difference in enterprise green growth efficiency in China during the above 3 years. Ranking the average efficiency from high to low, the order is as follows: the West, Central region, the Northeast and the East. Enterprise green growth efficiency shows a rising trend in the Northeast, and other regions show a downward trend. The enterprise green growth efficiency in the East is higher than the national average, and the efficiency in the other regions is less than the national average.
\end{abstract}

Keywords green growth; efficiency evaluation; DEMATEL-DEA; enterprises

Received January 8, 2015, accepted May 7, 2015

Supported by the National Natural Science Foundation of Major International Cooperation Projects (71320107006), the National Nature Science Foundation (71273037, 71303027), the Changjiang Scholars and Innovative Team Development Program Sponsored by the Ministry of Education (IRT13048), the Humanities and Social Science Youth Foundation of the Ministry of Education (12YJC630230), the Soft Science Project on Transportation of the Traffic Department (2013-322-225-240), the Fundamental Research Funds for the Central Universities Foundation (3132013336), and the Liaoning Province University Innovation Team Program (LT2013011) 


\section{Introduction}

The development of the world economy has encountered a huge bottleneck because of the energy crisis, climate change and environmental damage, and many countries have paid increasing attention to these problems. Energy conservation and consumption reduction, low-carbon development and green growth will factor into strategic decisions to address the major problems. Green growth as a concept was first proposed by the organization of economic cooperation and development (OECD); the core idea of green growth is to promote economic growth and development, and ensure that the natural resources can continue to provide resources and environmental services which human beings rely on. The effective protection of resources and the environment is a significant change to the traditional extensive mode of economic development in consideration of the situation of economic growth ${ }^{[1]}$. Economic development in China has been rapidly increasing since the reform and its opening up. The GDP increased from 364.52 billion yuan in 1978 to 47288.16 billion yuan in 2011, and the average annual growth rate is $15.9 \%$. The per capital living energy consumption has increased from 106.6 kgec in 1983 to $258.3 \mathrm{kgec}$ in 2010, which is a 2.4-fold increase. With the development of economic growth, energy consumption has also increased rapidly. With the amount of non-renewable energy decreasing, resources such as oil, coal and natural gas will be in greater demand. How to solve this problem has become an urgent issue not only for our country but all countries around the world. After the concept of green growth was brought forward, many countries attempted to adopt the policy of green growth, but success has not been widespread.

From the view of market demand, the current consumers around the world have been increasingly in the pursuit of green products and services. Economic development cannot occur without the modern enterprises that are the main carriers of green production. Enterprises play an important role in economic development, and an ecological civilization requires changing the mode of economic growth. Finally, enterprises are responsible for changing the mode of economic growth ${ }^{[2]}$. At the same time, the enterprises that pay attention to environmental problems can win the first mover advantage and market competitiveness by developing green innovation strategy, and those who do not take environmental issues into strategic consideration will face greater environmental risks and business uncertainty. Developing a green innovation strategy can allow an enterprise to cultivate new ability to adapt to the changes in the external environment and win a competitive position in the future ${ }^{[3]}$. Therefore, enterprises' green growth will become the main concern of all the countries in the world in the future.

In recent years, many domestic and foreign scholars have researched green growth. Grover ${ }^{[4]}$ analyzed the effect of India nuclear power development on the green growth in India. Resnick et al. ${ }^{[5]}$ took South Africa as the object to analyze the relationship between institutional policy and green growth. Mathews ${ }^{[6]}$ analyzed green growth strategy in South Korea and noted that the implementation of green growth was mainly through the promotion of the government. Lee ${ }^{[7]}$ analyzed the impact mechanism of green growth mode on policy. Han ${ }^{[8]}$ et al. studied innovation efficiency of various provinces in China using a 4 stage DEA model of spatial econometrics from the perspective of green growth. The results showed that environmental regulation had a significant influence on the growth of green innovation efficiency. Zhang and Wang ${ }^{[9]}$ calculated the index of green industrial growth in 2005-2009 in China and an- 
alyzed its influencing factor. The results showed that the local government had a significant effect on the degree of environmental protection. Zhang and Zhu ${ }^{[10]}$ calculated the technology innovation efficiency of industrial enterprises with a DEA model in various regions of China in 2009 based on the mode of green growth. The results showed that environmental factors could promote the technological innovation efficiency of industrial enterprises. Zhang ${ }^{[11]}$ analyzed the factors that influenced enterprises to implement green innovation based on a grounded strategy to provide reference for the government in the transformation of the enterprise management mode and to develop a regulation policy. Liu ${ }^{[12]}$ analyzed the relationship between green economic growth and capital investment structure using grounded theory in Henan.

Through the above analysis, we can see that the existing studies focus on the macro level analysis, and there are few scholars who study the combination of green growth and economic development. Enterprises are the core of economic development of a country, and enterprises will become an important way to achieve green economic growth in the future. Because the improvement of enterprises' green growth efficiency is the core problem of enterprise green development, this paper studies the evaluation of enterprise green growth efficiency with a DEA method and builds an evaluation model of enterprises' green growth efficiency based on an improved super efficiency DEA model under the background of analyzing the mode of green growth efficiency. The paper comprehensively evaluates the green growth efficiency of standardsized industrial enterprises in 31 regions in China in 2003, 2007, and 2012 to propose feasible suggestions for the transformation and upgrading of the enterprises in China and to provide scientific evidence to formulate an enterprise's green development strategy.

\section{The Method and Model}

This paper first selects an input and output index set of the evaluation of enterprise green growth efficiency based on the literature analysis and the actual development of enterprises and determines the weight of each index by the G1 method, which can avoid the error caused by excessive indexes, thus developing a direct impact matrix of every index through the size of the weight. The study then performs a system analysis on each indicator using DEMATEL to calculate the impact degree, impacted degree, centrality degree and reason degree and to determine the input and output index of the evaluation of enterprise green growth efficiency. After this, the enterprise green growth efficiency of 31 regions in China in different years is calculated with the super efficiency DEA model, and the pure technical efficiency and scale efficiency of enterprise green growth is calculated with the traditional DEA mode to analyze the return to scale. Specific research methods are as follows:

\subsection{The Model of DEMATEL ${ }^{[13]}$}

Bastille National Laboratory of American created a tool using graph theory and matrices to solve complex and difficult problems in the real world in 1971. The traditional DEMATEL method uses expert scoring to judge the effect of the relationship between the various influencing factors. However, if there are too many factors, the expert cannot easily find the relationship of various factors, and the scoring results might include error. On this basis, this paper firstly uses the G1 method to determine the weight of each index and then to determine the degree of influence index between the ratio of index weight. The specific application processes are as 
follows:

1) Determine the factors of the system

First, this paper analyses the probable input and output indexes of enterprise green growth efficiency according based on the research content, and the factors are as follows:

$$
G G O I_{11}, G G O I_{12}, G G O I_{13}, \cdots, G G O I_{n n}
$$

2) Establish the direct impact matrix

The direct impact matrix represents the relationship of direct influence of each factor and sets up the direct impact matrix $X=\left(G G O I_{i j}\right)_{n \times n}$. It then calculates the direct impact matrix according to the weight of G1 of each factor,

$$
X=\left(G G O I_{i j}\right)_{n \times n}=\left[\begin{array}{llll}
G G O I_{11} & G G O I_{12} & \cdots & G G O I_{1 n} \\
G G O I_{21} & G G O I_{22} & \cdots & G G O I_{2 n} \\
\vdots & \vdots & \ddots & \vdots \\
G G O I_{n 1} & G G O I_{n 2} & \cdots & G G O I_{n n}
\end{array}\right]
$$
other.

$G G O I_{i i}=0$ and $G G O I_{i j}=\frac{w_{i j}}{w_{i j}^{\prime}}$ represent the ratio of the weight between one index and the

3) Establish the comprehensive impact matrix

After the direct impact matrix $X$ is standardized, we obtain the impact matrix of standardization $Y$. The method of standardization is to take the maximum value of all elements in each row of the matrix and then divide the direct impact matrix by the maximum value. We obtain the direct impact matrix of standardization $Y$ through

$$
Y=X / \max _{1 \leq j \leq n} \sum_{j=1}^{n} I_{i j}=\left(I_{i j}\right)_{n \times n}
$$

Matrix $Y$ is standardized and dealt with in the following way

$$
G=Y(E-Y)^{-1}
$$

$E$ indicates a unit matrix, and $(E-Y)^{-1}$ is the inverse matrix of $(E-Y)$.

4) Factor's calculation results

Calculate the impact degree $D_{i}$, impacted degree $R_{i}$, centrality degree $M_{i}$ and reason degree $U_{i}$ by the comprehensive impact matrix,

$$
\begin{aligned}
& D_{i}=\sum_{j=1}^{n} G_{i j}, \quad i=1,2, \cdots, n \\
& R_{i}=\sum_{j=1}^{n} G_{j i}, \quad i=1,2, \cdots, n \\
& M_{i}=D_{i}+R_{i}, \quad i=1,2, \cdots, n \\
& U_{i}=D_{i}-R_{i}, \quad i=1,2, \cdots, n
\end{aligned}
$$

$D_{i}$ is the summation of the elements of each row of the comprehensive impact matrix, $R_{i}$ is the summation of elements of each column of the comprehensive impact matrix, the centrality degree $M_{i}=D_{i}+R_{i}$, and the cause degree $U_{i}=D_{i}-R_{i}$. 


\subsection{The Model of Super Efficiency DEA}

The DEA method, which is a CCR model, as an efficiency measurement method was first used by Charnes et al. ${ }^{[14]}$ under the assumption of fixed returns to scale. It obtained efficiency according to multiple sets of input and output dates using the principle of mathematical programming. Banker et al. ${ }^{[15]}$ proposed a more stringent correction model called BCC mode. It decomposed the technical efficiency of CCR model into the pure technical efficiency and the scale efficiency, namely, technical efficiency $=$ scale efficiency $\times$ pure technical efficiency. Then, the BCC model separated two reasons that caused technical invalidity (not in the best size and production technical inefficiency). The pure technical efficiency is more accurately reflected by the efficiency of the management level of the inspection object than the technology efficiency of the CCR mode in the case of exclusion of scale factors ${ }^{[16]}$; therefore, this study selects the BCC mode of the DEA model.

The DEA model can be divided into input oriented and output oriented. The former makes a minimum planning investment under a certain level of output; the latter makes a maximum planning investment under a certain level of input. In essence, they solve the same problem from a different perspective, and the final conclusion is identical ${ }^{[17]}$. Because the input variable is the basic variable of implementing the process of green growth, and it is easier to control compared to the efficiency of output, this study is based on the input-oriented DEA model.

When using the traditional DEA model to measure the efficiency evaluation unit, the result may include multiple evaluation units at the same time in the production frontier situation and may be relatively effective, so that the evaluation unit that is relatively effective cannot distinguish the difference in the efficiency value and affect the comparative differences among the evaluation units. To solve this problem, Fare et al. ${ }^{[18]}$ established the super efficiency DEA on the basis of the traditional DEA model to perform the comparative analysis of the difference in efficiency values among the relatively low values of effective evaluation units. The basic idea is as follows: When measuring an evaluation unit, the first step is to exclude it from the evaluation unit set. In Figure 1 and Figure 2, when measuring the efficiency value of evaluation unit $A$, it should be excluded from the participation set of the evaluation unit. The original frontier of $A$ turns from $\mathrm{SABS}^{\prime}$ to $\mathrm{SCBS}^{\prime}$, the efficiency value of $A$ is $\theta=O A^{\prime} / O A>1$, and the production frontier of inefficiency evaluation unit $C^{\prime}$ is SABS'. To effectively distinguish the difference in the evaluation unit, the efficiency value is 1 . Therefore, this paper evaluates the efficiency of the tourist industry of 31 regions in China based on the supper efficiency DEA model.

Assume that there are $K$ evaluated areas; each region has $N$ types of input factors of enterprises green growth and $M$ types of outputs from the input of enterprise green growth. The input set and output set of each region are expressed as: $x_{k}=\left(x_{1 k}, x_{2 k}, \cdots, x_{N k}\right), y_{k}=$ $\left(y_{1 k}, y_{2 k}, \cdots, y_{N k}\right)$, and the variable return to scale of the super efficiency DEA model based on the oriented input is expressed as: $x_{k}=\left(x_{1 k}, x_{2 k}, \cdots, x_{N k}\right), y_{k}=\left(y_{1 k}, y_{2 k}, \cdots, n y_{N k}\right)$, and the variable return to scale of the super efficiency DEA model based on the oriented input is expressed as:

$$
\theta^{*}=\min \theta
$$


Figure 2 The super efficiency DEA model

\section{Empirical Research}

\subsection{The Selection of Variables and Data Sources}

Pollutants generated from industrial enterprises in the development process account for a large proportion in all categories of enterprises. The pollution generated from the above designated size industrial enterprises has brought extremely limited economic development. The research objects of this paper are large scale industrial enterprises in China, and the green growth efficiency of the large scale industrial enterprises is evaluated. Considering that there are differences in regional economic and geographic conditions and because the input and output efficiencies of the green growth mode that the enterprises adopt are various in different regions, this paper takes 31 regions as the decision making units of the efficiency evaluation.

According to the literature analysis and the related statistical data, the efficiency of the input indexes of enterprise green growth include the total investment in environmental pollution control, environmental pollution control investment share of GDP, the environmental investment of completing the environmental acceptance projects this year, the urban environment infrastructure investment, the number of environmental acceptance projects this year, completion of investment of industrial pollution control, sources of forestry investment, and completion of the forestry investment. The output indexes include the main business income, total assets, fixed assets, owners' equity, total of current assets, main business taxes, total profits and other indexes. Because the DEA model limits the number of input and output indexes, this paper analyzes the input and output indexes on the basis of considering the impact degree, impacted degree, centrality degree and reasons degree of the various indexes by the DEMATEL method. Finally, it takes the total investment in environmental pollution control, the urban environment infrastructure investment, completion of investment of industrial pollution control, and completion of the forestry investment as input indexes of enterprise green growth efficiency and the main business income of the industrial enterprises and the total of the current assets as the output indexes, which are represented with the letters of EI, EII, IPI, FI, II, and CA. The unit of the six variables is billion yuan.

The policies and the degree of attention that enterprises paid to green growth are differ- 
ent in China in different periods of time, changing with the varying green growth efficiency. To determine the change in enterprises' green growth from the perspective of time, this paper takes 2003, 2007 and 2012 as the research time points. Research data come from the "China Environmental Statistical Yearbook", "China Statistical Yearbook", the national economic and social development statistical bulletin and government website. The characteristics of the variable data are shown in Table 1.

Table 1 Data characteristics of the input and output variables of enterprises' green growth efficiency (unit: Billion yuan)

\begin{tabular}{lllllll}
\hline \multirow{2}{*}{ Index } & \multicolumn{3}{c}{ The input index } & \multicolumn{2}{c}{ The output index } \\
\cline { 2 - 6 } & $E I$ & $E I I$ & $I P I$ & $F I$ & $I I$ & $C A$ \\
\hline Maximum value & 739.1 & 446.46 & 67.0633 & 690.3848 & 119286.8 & 46483.24 \\
Minimum value & 0.3 & 0.3 & 0.039 & 0.4349 & 19.96 & 26.68 \\
Mean & 101.8398 & 65.97629 & 7.76767258 & 46.09062 & 15829.89 & 6533.59258 \\
Median & 83.7 & 54.8 & 8.5644 & 17.7428 & 7510.67 & 3266.02 \\
Standard deviation & 168.9523 & 109.26004 & 11.737923 & 83.46672 & 22357.23 & 8431.71892 \\
Observation sample & 93 & 93 & 93 & 93 & 93 & 93 \\
\hline
\end{tabular}

\subsection{The Result of Enterprise Green Growth Efficiency}

On the basis of the super efficiency DEA model of investment and the variable returns to scale, this paper calculates the enterprises green growth efficiency in different regions in China with the DEAP software (Version 2.1) from the Coelli group design in 2003, 2007 and 2012, which takes the summation of the total amount of investment in environmental pollution control, investment in urban environmental infrastructure construction, the completion of the investment in industrial pollution control and the completion of forestry investment as the input variables and the main business income of standard-sized industrial enterprises and liquid assets as the output variables. The results are shown in Table 2 .

\subsection{Difference Analysis of the Overall Efficiency of Enterprise Green Growth}

As seen from Table 2, nationally, the overall efficiency of enterprise green growth showed a downward trend, decreasing from 0.825 in 2003 to 0.712 in 2012 . The average efficiency was 0.737 for 10 years. The level of the enterprise green growth efficiency needs to be further improved. The values of enterprise green growth efficiency changed significantly over the ten years. The highest efficiency reached 0.825 in 2003 , whereas the lowest efficiency reached 0.674 in 2007. A possible reason for this trend was that in 2003, China was in the "Tenth Five-year" period of development. During this period, the speed of economic development was relatively slow and the negative impact of enterprise development was smaller, but in 2007, China was in the "Eleventh Five-year" period of development, which emphasized rapid economic growth and neglected the governance of environmental issues. On December 25, 2009, the State Council held an executive meeting and decided that the carbon dioxide emissions per unit of GDP should be decreased $40 \% \sim 45 \%$ by 2020 compared to 2005 . During the two sessions in 2010 , the 
Table 2 Enterprises' green growth efficiency in China in multiple years

\begin{tabular}{|c|c|c|c|c|c|c|c|c|c|c|c|c|c|c|}
\hline \multirow{2}{*}{ order } & \multirow{2}{*}{ area } & \multicolumn{3}{|c|}{ crste } & \multicolumn{3}{|c|}{ vrste } & \multicolumn{3}{|c|}{ scale } & \multicolumn{3}{|c|}{ returns to scale } & \multirow{2}{*}{ the mean of crste } \\
\hline & & 2003 & 2007 & 2012 & 2003 & 2007 & 2012 & 2003 & 2007 & 2012 & 2003 & 2007 & 2012 & \\
\hline 1 & Beijing & 0.535 & 0.700 & 2.248 & 0.536 & 0.833 & 1.000 & 0.999 & 0.840 & 1.000 & $\operatorname{irs}$ & $\mathrm{drs}$ & - & 1.161 \\
\hline 2 & Tianjin & 0.861 & 0.638 & 1.259 & 1.000 & 0.916 & 1.000 & 0.861 & 0.696 & 1.000 & irs & irs & - & 0.919 \\
\hline 3 & Hebei & 0.492 & 0.494 & 0.541 & 0.493 & 0.496 & 0.557 & 0.997 & 0.997 & 0.972 & irs & irs & irs & 0.509 \\
\hline 4 & Shanghai & 2.403 & 0.902 & 1.812 & 1.000 & 0.902 & 1.000 & 1.000 & 1.000 & 1.000 & - & - & - & 1.706 \\
\hline 5 & Jiangsu & 0.801 & 0.691 & 0.911 & 1.000 & 0.829 & 1.000 & 0.801 & 0.833 & 0.911 & drs & drs & drs & 0.801 \\
\hline 6 & Zhejiang & 1.512 & 2.620 & 0.731 & 1.000 & 1.000 & 0.764 & 1.000 & 1.000 & 0.957 & - & - & drs & 1.621 \\
\hline 7 & Fujian & 1.208 & 0.637 & 0.368 & 1.000 & 0.764 & 0.376 & 1.000 & 0.834 & 0.979 & - & irs & irs & 0.738 \\
\hline 8 & Shandong & 0.547 & 0.560 & 0.517 & 0.548 & 0.594 & 0.864 & 0.999 & 0.943 & 0.599 & - & drs & drs & 0.541 \\
\hline 9 & Guangdong & 2.187 & 1.767 & 1.743 & 1.000 & 1.000 & 1.000 & 1.000 & 1.000 & 1.000 & - & - & - & 1.899 \\
\hline \multirow[t]{2}{*}{10} & Hainan & 0.700 & 1.423 & 0.114 & 0.701 & 1.000 & 0.979 & 0.999 & 1.000 & 0.116 & irs & - & irs & 0.746 \\
\hline & East & 1.125 & 1.043 & 1.024 & 0.828 & 0.833 & 0.854 & 0.966 & 0.914 & 0.853 & - & - & - & 1.064 \\
\hline 1 & Shanxi & 0.769 & 0.369 & 0.227 & 0.774 & 0.379 & 0.230 & 0.994 & 0.973 & 0.986 & irs & irs & irs & 0.455 \\
\hline 2 & Anhui & 0.670 & 0.447 & 0.645 & 0.677 & 0.452 & 0.681 & 0.990 & 0.989 & 0.948 & drs & irs & irs & 0.587 \\
\hline 3 & Jiangxi & 0.606 & 0.547 & 1.335 & 0.609 & 0.557 & 1.000 & 0.995 & 0.982 & 1.000 & irs & irs & - & 0.829 \\
\hline 4 & Henan & 0.708 & 0.570 & 1.006 & 0.714 & 0.576 & 1.000 & 0.991 & 0.988 & 1.000 & drs & irs & - & 0.761 \\
\hline 5 & Hubei & 0.927 & 0.477 & 0.616 & 0.929 & 0.478 & 0.644 & 0.998 & 0.998 & 0.956 & drs & irs & irs & 0.673 \\
\hline 6 & Hunan & 1.003 & 0.475 & 0.457 & 1.000 & 0.481 & 0.463 & 1.000 & 0.989 & 0.986 & - & irs & irs & 0.645 \\
\hline
\end{tabular}


Table 2 (Continued)

\begin{tabular}{|c|c|c|c|c|c|c|c|c|c|c|c|c|c|c|}
\hline \multirow{2}{*}{ order } & \multirow{2}{*}{ area } & \multicolumn{3}{|c|}{ crste } & \multicolumn{3}{|c|}{ vrste } & \multicolumn{3}{|c|}{ scale } & \multicolumn{3}{|c|}{ returns to scale } & \multirow{2}{*}{ the mean of crste } \\
\hline & & 2003 & 2007 & 2012 & 2003 & 2007 & 2012 & 2003 & 2007 & 2012 & 2003 & 2007 & 2012 & \\
\hline & Middle & 0.781 & 0.481 & 0.714 & 0.784 & 0.487 & 0.670 & 0.995 & 0.987 & 0.979 & - & - & - & 0.658 \\
\hline 1 & Neimenggu & 0.388 & 0.253 & 0.261 & 0.388 & 0.257 & 0.272 & 1.000 & 0.983 & 0.959 & - & $\operatorname{irs}$ & $\operatorname{irs}$ & 0.301 \\
\hline 2 & Guangxi & 0.484 & 0.215 & 0.469 & 0.485 & 0.216 & 0.481 & 0.998 & 0.995 & 0.976 & $\operatorname{irs}$ & irs & $\operatorname{irs}$ & 0.389 \\
\hline 3 & Chongqing & 0.423 & 0.297 & 0.806 & 0.423 & 0.299 & 0.845 & 0.999 & 0.996 & 0.954 & - & irs & $\operatorname{irs}$ & 0.509 \\
\hline 4 & Sichuan & 0.502 & 0.420 & 0.811 & 0.517 & 0.420 & 0.817 & 0.972 & 0.999 & 0.993 & drs & $\operatorname{irs}$ & $\operatorname{irs}$ & 0.578 \\
\hline 5 & Guizhou & 0.953 & 0.514 & 0.298 & 0.959 & 0.539 & 0.402 & 0.993 & 0.953 & 0.740 & drs & irs & irs & 0.588 \\
\hline 6 & Yunnan & 0.920 & 1.436 & 0.265 & 0.926 & 1.000 & 0.271 & 0.994 & 1.000 & 0.976 & irs & - & $\operatorname{irs}$ & 0.874 \\
\hline 7 & Xizang & 1.126 & 0.885 & 0.589 & 1.000 & 1.000 & 1.000 & 1.000 & 0.856 & 0.588 & - & irs & irs & 0.867 \\
\hline 8 & Shaanxi & 0.583 & 0.464 & 0.309 & 0.598 & 0.465 & 0.329 & 0.974 & 0.997 & 0.941 & drs & irs & irs & 0.452 \\
\hline 9 & Gansu & 0.739 & 0.297 & 0.189 & 0.757 & 0.312 & 0.238 & 0.977 & 0.952 & 0.794 & drs & irs & irs & 0.408 \\
\hline 10 & Qinghai & 1.079 & 0.718 & 0.363 & 1.000 & 0.755 & 0.693 & 1.000 & 0.951 & 0.524 & - & irs & irs & 0.720 \\
\hline 11 & Ningxia & 0.238 & 0.168 & 0.263 & 0.266 & 0.873 & 1.000 & 0.896 & 0.192 & 0.263 & irs & $\operatorname{irs}$ & $\operatorname{irs}$ & 0.223 \\
\hline \multirow[t]{2}{*}{12} & Xinjiang & 0.252 & 0.384 & 0.265 & 0.254 & 0.395 & 0.304 & 0.994 & 0.971 & 0.870 & irs & irs & irs & 0.300 \\
\hline & West & 0.641 & 0.504 & 0.407 & 0.631 & 0.544 & 0.554 & 0.983 & 0.904 & 0.798 & - & - & - & 0.517 \\
\hline 1 & Liaoning & 0.542 & 0.560 & 0.953 & 0.542 & 0.561 & 1.000 & 0.999 & 0.996 & 0.953 & drs & irs & drs & 0.685 \\
\hline 2 & Jilin & 0.992 & 0.506 & 0.965 & 1.000 & 0.514 & 0.982 & 0.992 & 0.984 & 0.983 & drs & irs & irs & 0.821 \\
\hline \multirow[t]{2}{*}{3} & Heilongjiang & 0.419 & 0.456 & 0.733 & 0.422 & 0.463 & 0.748 & 0.994 & 0.986 & 0.981 & drs & irs & irs & 0.536 \\
\hline & Northeast & 0.651 & 0.507 & 0.884 & 0.655 & 0.513 & 0.910 & 0.995 & 0.989 & 0.972 & - & - & - & 0.681 \\
\hline & mean & 0.825 & 0.674 & 0.712 & 0.726 & 0.623 & 0.708 & 0.981 & 0.931 & 0.868 & - & - & - & 0.737 \\
\hline
\end{tabular}


low-carbon economy was discussed as an important issue, and energy saving and green growth gradually became the core concerns of the Chinese government. In the planning of the "Twelfth Five-year", the goal was set that energy consumption per unit of GDP should be reduced $16 \%$ and carbon dioxide emissions per unit of GDP should be reduced $17 \%$. The economic growth rate by "Eleventh Five-year" of $7.5 \%$ was adjusted to $7 \%$, and the development of strategic emerging industries was greatly advocated during the "Twelfth Five-year". This series of national policy guidance had an effect on the variation of enterprise green growth efficiency.

\subsection{Difference Analysis of the Regional Efficiency of Enterprise Green Growth Efficiency}

1) The eastern region: The region includes ten provinces, and its mean enterprise green growth efficiency was 1.064, higher than the nationwide average level. This level was the highest nationwide. For enterprise green growth efficiency, the overall trend is downward, but in Beijing, Tianjin, Hebei and Jiangsu, it increased, especially in Beijing. There was a clear increasing trend in Liaoning, Beijing, Shanghai, Zhejiang and Guangdong, with values higher than the mean efficiency in the east. The average value of green growth efficiency for other enterprises was lower than the mean of the east. In Hebei and Shandong, it was also lower than the national average. These phenomena indicate that the enterprise green growth efficiency in the east had a higher status due to the contribution of Beijing, Shanghai, Zhejiang and Guangdong. From the point of view of pure technical efficiency, in the east, enterprise green growth was increasing. Namely, the technical capabilities of eastern enterprises were gradual increasing, which will help the enterprises to enhance the green growth efficiency in the future. However, the eastern enterprises green growth scale efficiency was declining, especially in Jiangsu, Zhejiang and Shandong, where the scale efficiency significantly decreased, indicating that the three areas should have properly controlled enterprise operating scales to improve the green growth efficiency.

2) The central region: The region includes six provinces, and its mean enterprise green growth efficiency was 0.658 , lower than the nationwide average level. This level was the third highest nationwide. Enterprise green growth efficiency was in decline. In Jiangxi and Hunan, it was rising and reached greater than 1 in 2012. In Anhui, it declined slightly, and in Shanxi, Hubei and Hunan, it declined significantly. However, the efficiency of Hunan was in an effective state in 2003. The pure technical efficiency and scale efficiency of the central enterprise green growth both tended to decrease, but the scale efficiency declining trend was smaller. From the perspective of returns to scale, the scale benefit of Shanxi, Anhui, Hubei and Hunan were all in incremental stages; namely, enterprises should enhance the green growth efficiency through appropriately expanding the operation scale.

3) The western region: The region includes twelve provinces, its mean enterprise green growth efficiency was 0.517 , lower than the nationwide average level, and this level was the lowest nationwide. Enterprise green growth efficiency was in obvious decline overall. Chongqing, Sichuan, Ningxia and Xinjiang were increasing, but the other provinces showed a downward trend. Guizhou, Yunnan, Tibet, Gansu and Qinghai declined significantly, but the enterprise green growth efficiency of Tibet and Qinghai were in an effective state in 2003. The pure technical efficiency and scale efficiency of enterprise green growth were both in decline in the western 
region, indicating that the western enterprises had a high potential for efficiency gains from a technical aspect. As seen from the returns to scale, the western enterprises scale benefit was in incremental stages, namely, enterprises should enhance the green growth efficiency through appropriate upgrading of the operating scale.

4) The Northeastern region: The region includes three provinces, its mean enterprise green growth efficiency was 0.681 , lower than the nationwide average, and this level was the second highest nationwide. It had a distinct gap with the eastern region. Enterprise green growth efficiency was on the rise overall, but in Jilin, it declined significantly. In Jilin, the mean enterprise green growth efficiency was the highest of the northeast region. In Liaoning and Heilongjiang, it was lower than the mean efficiency in the northeast. In the Northeast, the pure technical efficiency of enterprise green growth showed a clear upward trend, but the scale efficiency was in obvious decline. Jilin and Heilongjiang had the potential to expand the scale of operation to improve green growth efficiency.

\section{Conclusions and Discussion}

This paper measured the enterprise green growth efficiency in 31 regions in China based on the super efficiency DEA model of investment-oriented variable returns to scale for 558 sample data points over three years $(2003,2007$, and 2012). The study analyzed the regional differences and trends of enterprise green growth efficiency, and the conclusions are as follows:

1) By analyzing the data, we can see that the ranking of regional enterprise green growth efficiency is: the eastern, northeastern, central, and western regions. The main reason for this result is that enterprise green growth efficiency in the eastern cities, such as Beijing, Shanghai, Zhejiang and Guangdong, is at a higher level, whereas in the western cities, such as Ningxia, Xinjiang, Inner Mongolia and Guangxi, it is at a low level. The different levels have a deep impact on the two areas.

2) We can see that the change of the country's overall development strategy and policy have a strong influence on enterprise green growth efficiency based on the change of enterprise green growth efficiency in 31 regions in 2003, 2007 and 2012. From the Tenth Five-year to Twelfth Five-year, enterprise scale and the speed of development gradually improved. Attention to enterprises technical ability also gradually increased, and the transition in the mode of economic development was also paid more attention. The economic growth changed from slow to rapid and from excessive to stable development, and in this course, the enterprise green growth efficiency also changed gradually.

3) According to the evaluation results of enterprise green growth efficiency, this paper systematically analyzed the differences of enterprise green growth efficiency and its trends among regions in China. The factors that lead to the differences and the changing trend were also analyzed. However, the causes of the differences between the green growth efficiency of each area were not deeply analyzed from a quantitative point of view. Econometrics will be used to identify the influencing factors of enterprise green growth efficiency in China in the future. 


\section{References}

[1] Wang Y J, Lin W B. Transformation of economic development mode and green growth. Review of Economic Research, 2011(1): 3-12.

[2] Lao K F. Research on mechanism of consumer innovativeness influences green consumption behavior. Nankai Business Review, 2013, 16(4): 106-113.

[3] Hamel G, Prahalad C K. Corporate imagination and expeditionary marketing. Harvard Business Review, 1991, 69(4): 81-92.

[4] Grover R B. Green growth and role of nuclear power: A perspective from India. Energy Strategy Reviews, 2013, 1(4): 255-260.

[5] Resnick D, Tarp F, Thurlow J. The political economy of green growth: Cases from Southern Africa. Public Administration and Development, 2012, 32(3): 215-228.

[6] Mathews J A. Green growth strategies - Korean initiatives. Futures, 2012, 44(8): 761-769.

[7] Lee J. Examining a green growth model for policy implications. Seoul Journal of Economics, 2012, 25(1): $57-87$.

[8] Han J, Song T, Chen C F, et al. Research on regional innovation efficiency based on green growth in China. Comparative Economic \& Social Systems, 2013(3): 100-110.

[9] Zhang J X, Wang X W. Research on measurement and influencing factors of the industrial green growth index by region in China. Soft Science, 2013, 27(10): 92-96.

[10] Zhang J X, Zhu L. Research on technological innovation efficiency of industrial enterprises based on green growth of regions in China. The Journal of Quantitative \& Technical Economics, 2012, 2(12): 113-124.

[11] Zhang G, Zhang X J. Driving factors of green innovation strategy: Multiple case study. Journal of Zhejiang University (Humanities and Social Sciences), 2014, 44(1): 113-124.

[12] Liu J. Capital investment structure and henan green economic growth based on ridge regression. Contemporary Economics, 2014(4): 4-5.

[13] Ting C W, Huang J W, Wang D S, et al. Combining DEMATEL with ANP to modify multidimensional scaling in identifying the similarities of e-shopping stores. African Journal of Business Management, 2013, $7(22):$ 2206-2218.

[14] Charnes A, Cooper W W, Rhodes E. Short communication: Measuring efficiency of decision making units. European Journal Operational Research, 1979, 3(4): 339.

[15] Banker R D, Chaenes A, Cooper W W, et al. Constrained game formulations and interpretations for data envelopment analysis. European Journal of Operational Research, 1989, 40(3): 299-308.

[16] Huang X, Yu D, Yang L. Research on the X-efficiency of commercial banks in China. The Journal of Quantitative \& Technical Economics, 2008(7): 80-91.

[17] Charnes A, Cooper W W, Rhodes E. Measuring efficiency of decisionmaking units. European Journal of Operational Research, 1978, 2(6): 429-444.

[18] Fare R, Grosskopf S, Lovell C A K, et al. Mul-tilateral productivity comparisons when some outputs are undesirable: A nonparametric approach. The Review of Economics and Statistics, 1989, 71(1): 90-98. 